\section{Current Advances in Surgery} Mario A Trelles*

Instituto Medico Vilafortuny Av. Vilafortuny, 31 E43850, Cambrils, Tarragona, Spain

At present medicine is progressing in a non-stoppable course. Advances occur regularly and each basic discovery, each healing effect observed is rapidly linked to a practical clinical application. There is an increased interest in validating if not stopping the biological clock. In the area of rejuvenation and anti aging it is not only changes in cell and their extra cellular matrix, persistence of the subcutaneous fat layer, tissue firmness, luminosity, volume, and skin elasticity which are needed to maintain a fresh skin free of wrinkles and pigment but it is more than this. The whole process is in fact a complex combination of a variety of biological elements and processes which start the path leading to anti-aging. Infighting this, the face, bones, muscles, fat and skin are all involved and should receive proper care. This said, it is necessary to assume that to battle against all these circumstances makes it compulsory to use a combination of therapeutical approaches.

Doctors of various specialities, together with scientists and with the help of new instrumentation are the key to go forward: taking advantage of all resources will make the work of medical professionals easier and more effective.

Allow me to focus on my speciality as plastic-aesthetic surgeon, where advances have been significant. Autologous fat transplants and its long permanence in new refilled areas; artificial material for replacing tissue loss, the use of Botulinum Toxin to monitor and soften facial expressions, and to govern muscle contraction; together with the comprehension of the benefits of the residual thermal deposit when using lasers, RF and IPL devices for cutaneous rejuvenation, represent advances in less invasive surgery. New techniques in addition to the vast therapeutic offer, makes it possible to obtain great cosmetic results, more efficiently and with less down time. I am sure that I am forgetting various modalities and treatment techniques also used today but basically, what is important is that at present progress involves a combination of therapeutical approaches in order to achieve the best possible outcome. This is the way that we are advancing and foresee will continue to be so. However, in order to have the maximum benefit of all possible therapeutical opportunities, from my personal view point, I believe that rationalism should impose. I consider this of importance because, for progress and in order to face evident and positive results we should keep the following in mind:

- Advances must be based on priorities, assigning death lines and times to achieve a result which has been identified as a compromise with the purposes of treatment.

- In order to achieve goals, a plan of action with close regards to various tasks and functions should be clearly defined. Indentifying which of the tasks needed to be carried out is most necessary and which of these will give a more immediate reward.

- Self discipline should be compulsory to reduce interruptions and avoid unforeseen problems and obstacles that will distract advancing. Work should be a synonym of objectives achievements, hand in hand with goals.

- A continuous check-up of our work mode should take place, basically at the termination of work and its initiation, the following day. It is at this moment that areas which need attention have to be identified to assign a proper plan of action. These actions go together with systematization, commitment and enthusiasm, maintaining order and priorities in our daily actions.
*Corresponding author: Mario A Trelles, Instituto Medico Vilafortuny Av. Vilafortuny, 31 E43850, Cambrils, Tarragona, Spain, Tel: +34977361320; Fax: +34977791024; E-mail: imv@laser-spain.com

Received December 17, 2013; Accepted December 24, 2013; Published January 02, 2014

Citation: Trelles MA (2014) Current Advances in Surgery. Surgery Curr Res 1 : e111. doi:10.4172/2161-1076.1000e111

Copyright: ( 2014 Trelles MA. This is an open-access article distributed under the terms of the Creative Commons Attribution License, which permits unrestricted use, distribution, and reproduction in any medium, provided the original author and source are credited. 